\title{
A ORGANIZAÇÃO PICTÓRICA DE UM PERCURSO PLÁSTICO NO PENSAMENTO DE MERLEAU-PONTY: DA EXPERIÊNCIA PERCEPTIVA À VISÃO DO MUNDO SELVAGEM
}

\author{
The pictorial organization of a plastic path in Merleau-Ponty thoughts: from perceptive \\ experience to wild world vision
}

Plínio Santos Fontenelle

UFMA

O artista é aquele que fixa e torna acessivel aos demais humanos o espetáculo de que participam sem perceber.

Quando percebo, não penso o mundo, ele organiza-se diante de mim. (Merleau-Ponty)

\begin{abstract}
Resumo: O presente artigo discute a questão do percurso plástico do pintor Paul Cézanne e a influência direta vivida por Merleau-Ponty nas fases da fenomenologia e da ontologia selvagem. Para tanto, o referido percurso é sustentado pelo tema da organização estruturante das obras de arte que "lançam" os sujeitos da percepção ao mundo vivido. Na fase fenomenológica mostramos o problema da percepção das imagens a partir das criações romântica e impressionista de Cézanne, pintor moderno, que critica a produção clássica pelo poder de representação da natureza em suas formas "nítidas" e delimitadas, por exemplo, pelas linhas e pelos desenhos, estabelecendo-se, a partir dessa questão, a ultrapassagem do mundo determinado. Em seguida, pretendemos mostrar como a pintura do último Cézanne encontra-se aberta, enquanto pintura "selvagem", ao sujeito e ao mundo, na condição de envolvimento carnal. Desse modo, passamos a compreender questões fundamentais como: o olhar e a experiência perceptiva; o processo de criação pictórica; a constância e os instantes do mundo; a profundidade, a visão radical e a ontologia selvagem.
\end{abstract}

Palavras-chave: Paul Cézanne; Pintura; Percepção; Visão; Ontologia; Merleau-Ponty.

Abstract: This article discusses the question of path plastic of the printer Paul Cézanne and the direct influence lived for Merleau-Ponty in the phases of phenomelogy and wild ontology. Therefore, the plastic path is supported for the theme of the structural organization of works of art that "shows" to the subject of perception the world lived. In the phenomenology phase we show the problem of perception of pictures from the romantic and impressionists creations of Cézanne, a modern printer, who criticizes the classic production for the power of representation of the nature in sharp and delimited forms, for example, for lines and drawings, establishing, this way the question that are beyond the world determined. Then, we intend to show how the painting of the "last" Cézanne is opened while wild painting to the subject and to the world, in condition of carnal involvement. This way, we begin to understand 
question how: the look and the perceptive experience, the process of pictorial creation, the moments of the world; the depth, the radical vision and the wild ontology.

Keywords: Paul Cézanne; Painting; Perception; Vision; Ontology; Merleau-Ponty.

\section{Introdução}

Por ocasião da nossa tese de doutoramento analisamos questões relativas à estética do fenomenólogo francês, Maurice Merleau-Ponty (1908-1961) envolvido basicamente com os trabalhos pictóricos do então singular Paul Cézanne (1829-1906), que nos traz também questões importantes de "regiões" nas quais o ser está implantado. Logicamente não nos referimos a idealidades enquanto fatos a priori de uma consciência, mas de um trabalho que conseguiu representar com as cores densas, escuras ou claras, os gestos de todas as interrogações do ser, ou porque não dizer, os traços e mesmo as carências, conforme Merleau-Ponty, que se revelam nos outros; ou que se revelam em nossa frequentação do mundo. Nesta mesma inten ção, lembramos da referência feita por Shapiro ao pintor em questão, quando nos fala de Cézanne como um artista da "quebra" ou do "rompimento" (transgressão?) - às vezes, em total desacordo com ele próprio -, de modo a produzir enfrentamentos com a cópia ou até mesmo sustentar a volubilidade das cores. Podemos ler tais incertezas enquanto passos de uma "instabilidade" pictórica, aliás, desde o início de suas intenções de pintar, quando da relação esvaziada com seu pai, que o exigiu seguir a carreira no Direito ou ser bancário, sendo este uma vez, o financiador de algumas incursões de Cézanne à Paris, mesmo a contragosto.

Conforme este aspecto biográfico exposto em quase todos os estudos a respeito do pintor francês, não pretendemos suscitar fatos específicos vividos por ele e sua relação com os mestres, com os pares impressionistas ou com os salões da capital Paris, mas objetivar um percurso que encontra na própria vida - e também nessas relações -, as marcas de uma incontestável natureza humana que pode estar entregue, inclusive, ao "caos das sensações"1.

\footnotetext{
${ }^{1}$ MERLEAU-PONTY, Maurice. A dúvida de Cézanne. (Os pensadores) Trad. Marilena Chauí. São Paulo: Abril Cultural, 1975, p. 306.
} 
Apostamos em um esquema que pode ser definido nestes escritos como a peculiar expressão das imagens pictóricas de Paul Cézanne a partir de um percurso plástico reinvestido no pensamento de Merleau-Ponty. Por certo que o referido filósofo não demarca separadamente as fases da experiência estética de Cézanne no início de seu aprendizado e dos contatos com pintores famosos até o momento em que extrapola a percepção da natureza. Mas é nesta direção que queremos apostar em duas hipóteses que se inter-relacionam: a primeira, diz respeito ao percurso plástico de Cézanne que inspirou as teses de Merleau-Ponty, que vão da fenomenologia à nova ontologia expostas intensamente em obras como $A$ dúvida de Cézanne e em $O$ olho e o espírito (se quisermos escolher prontamente, as duas principais representantes das fases referidas); e a segunda, diz respeito à organização de um pensamento a partir da organização de uma pintura, ou seja, levantamos a ideia que o percurso plástico estruturante de Cézanne está incorporado como inspiração franca e, portanto, expressiva, na "estrutura" reflexiva de Merleau-Ponty. ${ }^{2}$

Essa ideia de um percurso pictórico estar em reciprocidade com um pensamento, entendendo-se aqui a reciprocidade por seu caráter ontológico e pensado no concreto significado de empiètment, nos leva a pensar que as três fases do pintor de Aix-en-Provence - arriscando-nos claramente a examinar que Cézanne, do começo de suas relações de aprendizagem às tarefas de um pintor que influencia o movimento cubista -, tem em cada momento, dados de mundo que intensificam as reflexões de Merleau-Ponty "lançado" às coisas mesmas e, depois, ao reenvio de uma natureza inumana. Mas por onde começar a reciprocidade ou o entrecruzamento do trabalho da

\footnotetext{
${ }^{2}$ Estamos, por certo, na trilha de uma mesma tese, com a incontestável semelhança de características entre as partes apresentadas por nós. Contudo, as duas questões se sustentam em seus aspectos próprios, pois quanto à primeira é sempre atual nos aproximar das reflexões de Merleau-Ponty sobre a experiência perceptiva e sobre a carnalidade do corpo no mundo sensível, portanto, reflexões estéticas que têm como base os trabalhos pictóricos de vários criadores (sendo Paul Cézanne, o tema preferido); e em relação à segunda, porque a escolha de um itinerário cézanneano serve de análise, antes de tudo, para que o filósofo em questão compreenda o ato de criação das obras de arte pelo pintor, que leva em consideração, a sua organização estruturante de concepção/inspiração até o momento de "entrega" delas aos sujeitos da percepção, o que, no momento da ontologia carnal, as imagens das pinturas estarão no pacto visível entre o sujeito e o mundo, na condição de envolvimento carnal. Durante as explanações de nossas ideias, pode ser verificado que a organização pictórica restabelece o sentido de expressão como condição de superação do mundo pronto e acabado.
} 
pintura com o trabalho do pensamento? Melhor dizendo: por qual momento podemos iniciar a percepção da influência de Cézanne destacada no pensamento de MerleauPonty?

\section{O Cézanne romântico ou cores densas como dados fenomênicos}

\section{Sustentamos que é no ensaio $A$ dúvida de Cézanne o encontro mesmo com} as primeiras fases da obra do pintor, sobretudo, aquelas que se destinam a concretizar o pensamento fenomenológico ${ }^{3}$. Merleau-Ponty começa tal escrito referindo-se às dúvidas que assolam um trabalho promissor e de grande vocação, pois ele estuda o Cézanne indeciso e suscetível, mas um pintor devotado ao mundo sensível. "Pois desde 1852, em Aix, quando ingressou no Colégio Bourbon, Cézanne inquietava os colegas por suas cóleras e depressões". ${ }^{4}$

É neste momento que Merleau-Ponty expõe o Cézanne de 1852, bastante jovem e amigo de Émile Zola do Licée, estes que percorreram as cercanias da cidade natal já compreendendo o sentido da natureza. Mas é o amigo Zola que parece dar um impulso necessário aos estudos de Cézanne com certo insucesso. ${ }^{5} \mathrm{Nem}$ por isso deixa de reivindicar do pai, como afirma o próprio filósofo, as possibilidades de reencontrar sempre seus mestres em Paris e no Museu do Louvre. Ao Ihe ser negada qualquer

\footnotetext{
${ }^{3}$ Existem estudos que apontam que o referido ensaio não sustenta apenas os "dados" característicos de uma fenomenologia em Merleau-Ponty. Mesmo ela sendo escrita em 1942 e contemporânea de Fenomenologia da percepção, por sua igual publicação em 1945 (reaparecendo em Sens et non-sens em 1948), a obra em discussão sustenta questões relevantes, portanto, prévias, sobre a ontologia carnal, dada a ultrapassagem de Cézanne da pintura impressionista para a obra pictórica mais selvagem e de natureza inumana. Portanto, tais análises apostam n'A dúvida como um escrito de intercessão entre as questões fenomenológicas e as questões ontológicas do filósofo. Talvez mais diretamente não encontremos nenhuma expressão com os dados de sua segunda fase, mas questões como a profundidade, a vibração das aparências retiradas por influência do pintor em tela, conseguem já antecipar os temas ontológicos. A afirmação a seguir nos diz muito sobre esse sentido: "Vivemos em meio aos objetos construídos pelos homens, entre utensílios, casas, ruas, cidades e na maior parte do tempo só os vemos através das ações humanas de que podem ser os pontos de aplicações. Habituamo-nos a pensar que tudo existe necessariamente e é inabalável. A pintura de Cézanne suspende estes hábitos e revela o fundo de natureza inumana sobre o qual se instala o homem" (Ibidem., pp. 308-309. Grifos nossos).

${ }^{4}$ Ibidem., p. 303.

5 “Cada vez mais, descura os estudos de Direito para se dar por inteiro à pintura. É visto frequentemente no Museu Granet, onde se aplica a copiar as obras. No entanto, o seu pai continua a opor-se à sua partida para Paris e Zola, esse, impacienta-se. Ele conhece o caracter indeciso de Cézanne e censura-o por ele prosseguir de maneira tão frouxa no objetivo que determinou" (BECKS-MALORNY, Ulrike. Paul Cézanne (1839-1906): o pai da Arte Moderna. Lisboa: Taschen, 1996, p. 8).
} 
possibilidade, encontra-se submetido completamente com os estudos do Romantismo de Delacroix. E aqui nos deparamos com a primeira fase de Cézanne, por certo, um pintor inspirado no gênio romântico que se opôs à circunscrição da cor pelo desenho. Como afirma Becks-Malorny: “Cézanne realizou no total seis cópias de Delacroix, o pintor romântico que ele tanto venerou. Foi nele que aprendeu a exprimir por meio da cor as relações intrínsecas entre figuras e objetos" ${ }^{6}$ Essa compreensão de um forte romantismo vivido por Cézanne na primeira fase será objeto de análise merleaupontyana quando atenta para uma estética da expressão que não aprova as convenções acadêmicas e as "ordens" dos salões de beaux-arts; coincidindo inclusive com as questões de Gombrich sobre o nosso pintor: para se chegar à atmosfera dos aspectos a serem pintados, "Cézanne era sedento de cores fortes e intensas". ${ }^{7}$ Podemos retirar dessa ideia que Cézanne respeitava os mestres por seus contatos equilibrados com as formas, mas queria a sensação de repouso e de harmonia de outra maneira de fazer arte: queria entregar-se às próprias sensações. Assim, Merleau-Ponty nos fala dos primeiros quadros de Cézanne, desse pintor "romântico" que aposta na fuga do "mundo humano, [na] alienação de sua humanidade". ${ }^{8}$

Cézanne, com o romantismo do primeiro momento, visualizou uma atmosfera desconstruída da noção de cópia. As cores densas, como o negro, encobriam o desenho, intensificadas pela organização de um trabalho composto pela palheta de maneira totalmente diferente, ou seja, "o uso das cores quentes e do negro mostra que Cézanne quer representar o objeto, reencontrá-lo atrás da atmosfera". ${ }^{9}$ Vejamos que na pintura abaixo, mesmo sendo uma pintura organizada às portas de entrada do Impressionismo, ele mantém uma paleta escura e sombria, como se quisesse destacar o caráter dramático da paisagem pintada.

\footnotetext{
${ }^{6}$ Ibidem., p. 9.

${ }^{7}$ GOMBRICH, E. H. A história da arte. Trad. Álvaro Cabral. 16a ed. Rio de Janeiro: LTC, 1995, p. 539.

${ }^{8}$ MERLEAU-PONTY, Maurice. A dúvida de Cézanne. Op. cit., p. 304.

${ }^{9}$ Ibidem., p. 305.
} 


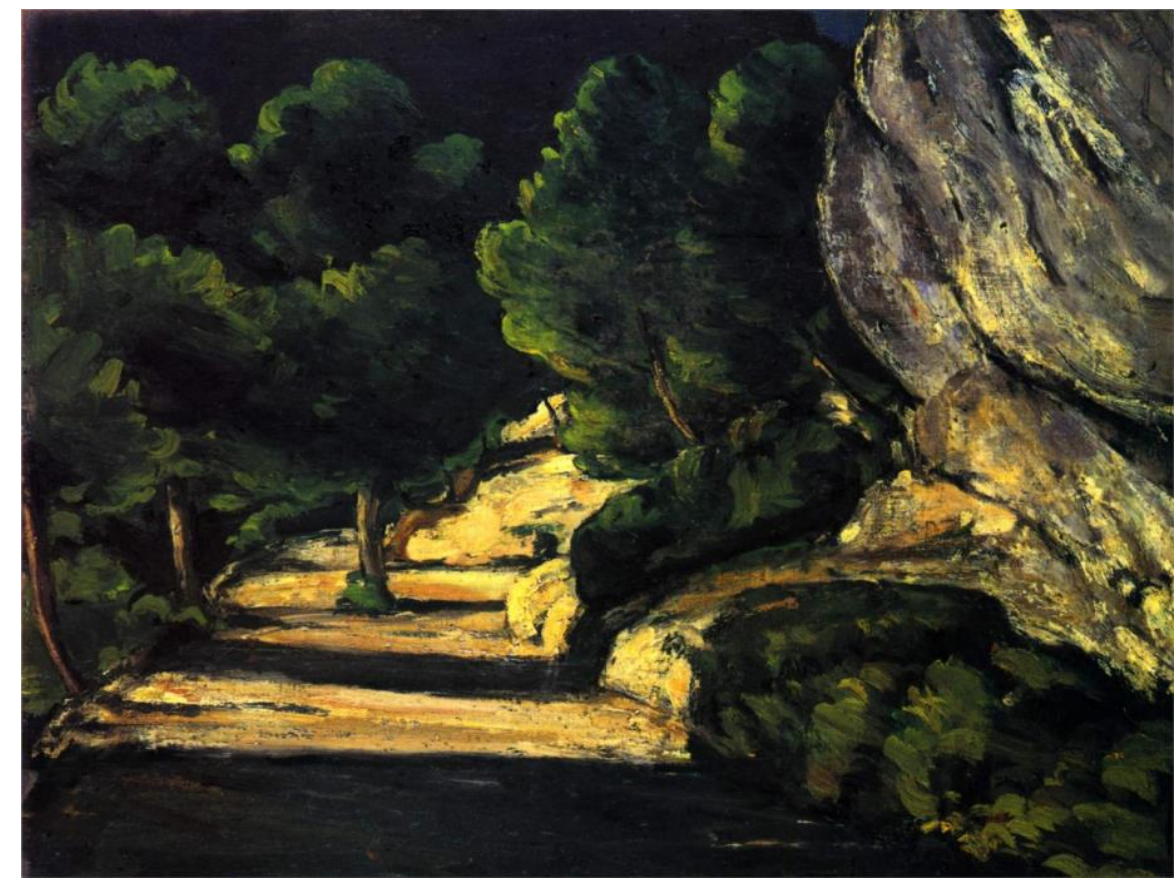

Fig. 1: $A$

Paisagem, 1870-1876

Como afirma Merleau-Ponty, os quadros românticos nada mais querem que sugerir "sentimentos e querem provocar primeiro os sentimentos. São então quase sempre pintados com grandes traços e dão antes a fisionomia moral dos gestos que seu aspecto visível" ${ }^{10}$ Pretende com esses gestos, imprimir uma distinção monumental aos aspectos da paisagem. Porém, essa organização no todo parecia não cumprir o que tinha aprendido. As inquietações persistiam e novos rumos apontavam para aquilo que chamamos de segunda fase. Comenta Merleau-Ponty a respeito:

A supressão dos contornos precisos em certos casos, a prioridade da cor sobre o desenho não terão evidentemente o mesmo sentido em Cézanne e no impressionismo. O objeto não fica mais coberto de reflexos, perdido em seu intercâmbio com o ar e com os outros objetos, é como que iluminado surdamente do interior, emana a luz e disso resulta uma impressão de solidez e materialidade. ${ }^{11}$

Pensamos nas possibilidades tênues em que Cézanne escolhe deslocar seu processo de organização pictórica para o momento puramente impressionista. No

\footnotetext{
${ }^{10}$ Ibidem., p. 304.

11 Ibidem., p. 305.
} 
campo estético, representar a natureza por um forte estado da alma configurado nas cores densas deve ser ultrapassado e por entender também que a representação não se harmoniza com a cópia. No entanto, a intenção com o criar ainda não se estrutura de modo radical ou selvagem - como dirá Merleau-Ponty -, por isso mesmo, o pintor francês não se descura da representação nesta fase, como querem os pintores modernos ao se contraporem à pintura clássica, pois mesmo parecendo paradoxal, concorda Merleau-Ponty, é "que os pintores clássicos eram pintores e nenhuma pintura clássica jamais consistiu em simplesmente representar". ${ }^{12}$

O que parece paradoxal dá-se, então, pela maneira como Merleau-Ponty propõe as imagens do mundo pela pintura moderna, capaz de "admitir uma verdade que não se assemelhe às coisas, que não tenha modelo exterior".${ }^{13}$ Ele atenta para o fato de que cada uma destas pinturas - clássica e moderna - possui seus próprios instantes, imbuídas de padrões básicos ligados ao processo de criação. Confirma nosso filósofo:

[...] a percepção dos clássicos se prendia à cultura deles, a nossa cultura ainda pode informar a nossa percepção do visível; não se deve abandonar o mundo visível às receitas clássicas, nem encerrar a pintura moderna no reduto do indivíduo, não se tem de escolher entre o mundo e a arte, entre os "nossos sentidos" e a pintura absoluta: estão todos entrelaçados. ${ }^{14}$

Essa referência a Cézanne e a maneira como este organiza suas experiências expressivas de conceber o mundo é conferida por Merleau-Ponty em todo o pensamento que pretende exaltar uma filosofia da visão, e encontra-se como projeto já no ensaio $A$ dúvida de Cézanne. É o que nos faz pensar o próprio filósofo quando nos mostra que a tradição e a ciência têm um sentido paradoxal em relação à atitude de serem elas "expressões segundas". Desse modo, a pintura de Cézanne "não nega a ciência e não nega a tradição". ${ }^{15}$ Ou se quisermos acrescentar:

\footnotetext{
${ }^{12}$ MERLEAU-PONTY, Maurice. Signos. Trad. Maria Ermantina Galvão Gomes Pereira. São Paulo: Martins Fontes, 1991, p. 49.

13 Ibidem., p. 59.

${ }^{14}$ Ibidem., p. 49.

${ }^{15}$ MERLEAU-PONTY, Maurice. A dúvida de Cézanne. Op. cit., p. 309.
} 
Em Paris, Cézanne ia diariamente ao Louvre. Pensava que se aprende a pintar, que o estudo geométrico dos planos e das formas é necessário. Informava-se sobre a estrutura geológica das paisagens. (...) Para todos os gestos que pouco a pouco fazem um quadro só há um motivo, a paisagem em sua totalidade e em sua plenitude absoluta - a que Cézanne justamente chamava "motivo". Começava por descobrir as bases geológicas. ${ }^{16}$

\section{As dúvidas encontram no Impressionismo a indubitável experiência perceptiva}

Parece que as dúvidas que Cézanne imprime às suas obras em nada justificam um modo de criação, mas justamente por se tratar deste pintor, as obras realizadas exigiam, por certo, essa vida em plena espontaneidade. Nestes termos, apostando no exato momento de "passagem" da influência romântica ao Impressionismo, e vislumbrando se os caminhos a seguir ainda deveriam estar na organização de uma quase-tradição ou nas bases científicas dadas às imagens pictóricas, ele conhece Camille Pissarro (1830-1903), que avista no amigo, certa necessidade de buscar um motivo constante para as obras, mesmo concebendo que a tradição lhe presenteara com muitos elementos e planos pictóricos para a criação.

Pissarro seguramente pode ser reconhecido como o maior professor de Cézanne na condição dessa "passagem" para o Impressionismo. A década de 1870 é a principal realização de um trabalho conjunto. Ele indicou a Cézanne a abandonar as cores fortes e escuras de seu modo de organização pictural; a paleta recebe as cores primárias (vermelho, amarelo e azul) e as derivações que delas podem resultar. ${ }^{17} \mathrm{E}$ conforme tais aspectos, o quadro A Vala (1867-1870) é apresentado como a obra que, pela primeira vez, sustenta os motivos impressionistas de um cromatismo luminoso, com cores claras e, ao fundo, a montanha de Santa Vitória que estará presente em sua produção artística até o último momento.

\footnotetext{
${ }^{16}$ Id. ibid.

17 "Pissarro recomenda-lhe igualmente que renuncie às formas e aos contornos lineares na elaboração de um motivo, devendo a aparência das coisas resultar da degradação das tonalidades. Ele aconselha-o a que não trabalhe pedaço a pedaço e a que aplique as cores observando exactamente as tonalidades em relação com o meio envolvente. Cézanne deve pintar com pequenas pinceladas tentando dar as suas sensações" (BECKS-MALORNY, Ulrike. Paul Cézanne (1839-1906): o pai da Arte Moderna. Op. cit., p. 21).
} 


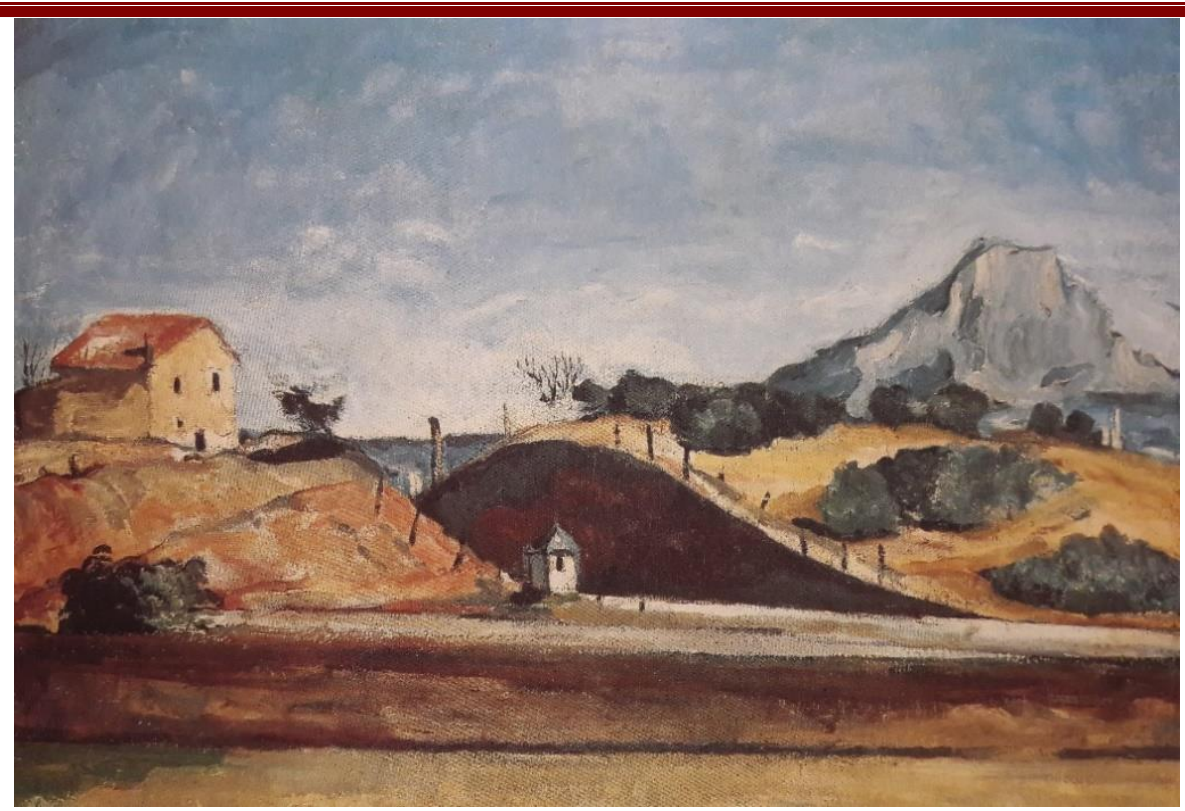

Fig. 2: A Vala com a montanha de Santa Vitória, 1867-1870

$\mathrm{Na}$ atmosfera do movimento impressionista da arte moderna, e na troca simples das cores intensas, Cézanne nunca deixou de pintar a natureza. Ela é o seu destaque. É neste sentido que o pintor, ao interrogar os diversos aspectos do ser, busca um apelo ao dehors, não a uma idealidade fixada enquanto obra do pensamento, mas que desempenhe a função ordinária de mostrar a paisagem na forma como é percebida. Pinta o que vê, a partir do mundo ao redor. Sobre essa questão, em diversos momentos do pintor verificamos expressões fundamentais que determinam o desenvolvimento de sua arte. Chama de petite sentation o modo simples como a natureza deva ser encarada. Cézanne quer, com isso, fazer uma releitura do fora utilizando-se da simplicidade para criticar a constituição tradicional na maneira de compreender o mundo pela pintura. $\mathrm{E}$ ele próprio não explorou nada de extraordinário.

Não há, em Cézanne, uma intenção deliberada de inovar, mas apenas de ver com seus próprios olhos. De fato, ele parte dos estilos constituídos e só os transcende à medida que a necessidade de acatar suas sensações o impele a construir sua visão. ${ }^{18}$

18 PEREIRA, Marcelo Duprat. A expressão da natureza na obra de Paul Cézanne. Rio de Janeiro: Sette Letras, 1998, p. 38. 
A visão construída será sempre o método intuitivo que Cézanne encontra para realizar a pintura, ou seja, o que pode passar despercebido no artista é uma certa concretização encontrada nas repetições de ações até chegar aos instantes do mundo que ele mesmo espera enquanto resultado; e para isso, é capaz de pintar por diversas vezes a mesma natureza.

Tal "visão" tem neste momento um significado crucial para aquilo que queremos sustentar enquanto a organização pictórica em nosso pintor, pois as "repetições" nada mais são que uma percepção decisiva dos detalhes da natureza, encontrados às vezes nos tons, na luz, na profundidade, enfim, e como nos diz MerleauPonty, Cézanne encontrará inclusive, o odor advindo da própria cor. E se quisermos fazer uma rápida alusão ao "último" Cézanne, as referidas repetições serão abandonadas num suporte que necessita de uma só pincelada. Mas a questão, por enquanto, está na ordem da natureza clara e de cores ofuscantes, exigindo do pintor várias sessões de trabalho numa mesma obra. Cézanne não estaria com essa proposta interrogando o mundo na constância visível das coisas através do trabalho que o desperta a cada manhã, conforme Merleau-Ponty? Por certo, a pintura é o resultado encontrado nas ações daquele que procura no mundo algo por pintar.

Cézanne se ajusta ao pensamento merleau-pontyano também nesta característica, por experimentar a constância dos sulcos, as ranhuras dos solos ou os traçados da vegetação, na cumplicidade da percepção. A constância aqui, na consecutiva organização de trabalho, não se justifica enquanto convenção, pois a natureza cézanneana é incompatível com toda possibilidade de um espetáculo pronto e acabado se for levada em conta a experiência do olhar; e, a maneira como o pintor se volta ao mundo pela sua arte, nunca leva a cabo o poder de "reconstituição das aparências". ${ }^{19}$ Isso nos leva a pensar que tal indeterminação da pintura inspirou Merleau-Ponty ao tema de indeterminação do mundo. A indeterminação da pintura que percorre o mesmo sentido de indeterminação do mundo se encontra de maneira

\footnotetext{
${ }^{19}$ MERLEAU-PONTY, Maurice. A prosa do mundo. Trad. Paulo Neves. Edição e prefácio de Claude Lefort.
} São Paulo: Cosac \& Naif, 2002, p. 92. 
peculiar na seguinte passagem sobre a pintura Árvores no Jas de Bouffan (1875-1876) de Cézanne:

É nesta paisagem que Cézanne encontra as estruturas essenciais e imutáveis da natureza, que mal estão sujeitas às mudanças dos anos ou das horas do dia. A permanência da vegetação, que se traduz pela folhagem sempre verde das oliveiras, dos pinheiros, dos ciprestes e dos carvalhos, convém à sua maneira lenta de trabalhar: mesmo que ele fique vários meses perante uma paisagem, esta quase se não modifica. Ele pode, com toda tranquilidade e obedecendo a uma disciplina severa reconstruir na tela a natureza segundo as suas concepções. ${ }^{20}$

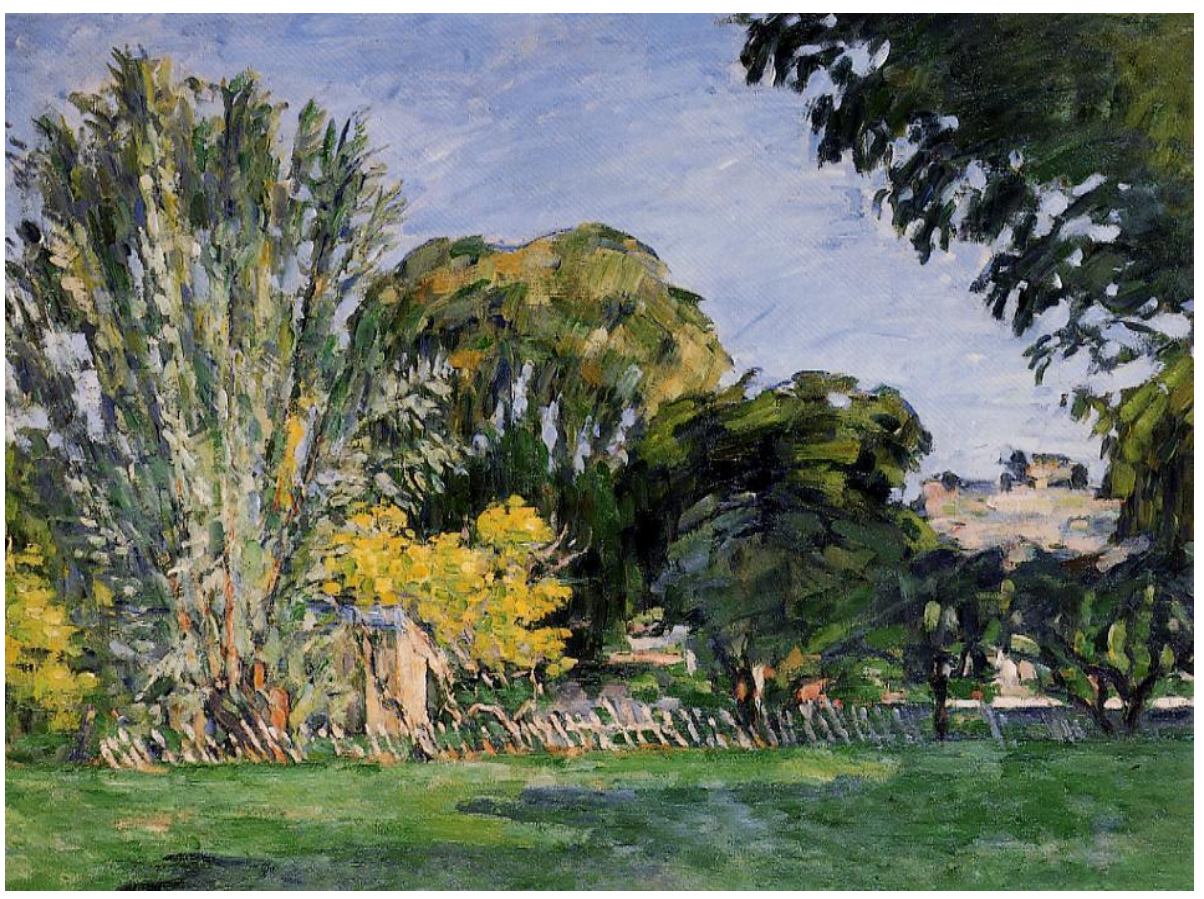

Fig. 3: Árvores no Jas de Bouffan, 1875-1876

Assim, pelas inúmeras pesquisas realizadas sobre o entrecruzamento entre Cézanne e Merleau-Ponty, em que o pintor é citado em várias obras durante o "percurso", o filósofo aposta, desde os primeiros instantes, num viés fenomenológico daquele. "O envolvimento recíproco da fenomenologia, tal que pratica Merleau-Ponty, e da pintura, no projeto inovador de Cézanne, faz deste último o arauto do mundo fenomenal", ${ }^{21}$ contudo, o pintor abraça um sistema próprio de elaboração fértil.

20 BECKS-MALORNY, Ulrike. Paul Cézanne (1839-1906): o pai da Arte Moderna. Op. cit., p. 37. Grifos nossos.

${ }^{21}$ BONAN, Ronald. Aprendre à philosopher avec Merleau-Ponty. Paris: Ellipses, 2010, p. 70. 
Este aspecto da "constância" que se encontra em destaque para a fenomenologia de Merleau-Ponty suscita a partir dos trabalhos de Cézanne, sobretudo nesta fase impressionista, a condição como este último tentou adequar a natureza às imagens pictóricas. As dúvidas de Cézanne ao reivindicar tal intento encontram-se na forma inesgotável com que a natureza se manifesta. O "sistema próprio" lhe permitia traçar aspectos da natureza por diversas vezes a cada contato perceptivo. "Retornar" a natureza às telas para o pintor não seria o mesmo que absorvê-la nitidamente conforme os padrões de linhas e contornos que configuram uma paisagem. Não imitar o objeto tal e qual como faz a representação clássica seria concentrar esforços na existência que está sempre por recomeçar.

Merleau-Ponty faz referência à "vida recomeçada" definindo que o estilo dos pintores modernos nunca está ligado a um meio próprio, particular e fechado do jeito como organizam suas obras. Ele se ajusta a Cézanne sobre tal característica, porque consegue ver no pintor, o modo universal como encara o trabalho de criação. Para nosso filósofo parece que ter "estilo" nunca será o mesmo que fechar-se em seu próprio "estilo"; afirma, diante disso, que

[...] é essa própria vida na medida em que ela sai de sua inerência, deixa de usufruir a si mesma, e torna-se meio universal de compreender e fazer compreender, de ver e dar a ver - portanto não encerrado nas profundezas do indivíduo mudo, mas difuso em tudo quanto vê. ${ }^{22}$

Entre os historiadores da arte, talvez seja ponto pacífico determinar a técnica do cromatismo entre todos os impressionistas. E com ela, de fato, nosso filósofo concorda que se trata de um meio peculiar de levar a percepção do mundo ao processo de criação pictórico. Mas mesmo sabendo-se da concordância de Cézanne na forma quase igual de captação das "impressões" entre seus pares - cada um adequando-se às organizações da maneira de pintar -, procurou em determinado momento, uma maneira própria de ver a paisagem e as coisas do meio ambiente da forma mais natural possível. Só que esse "estilo" se fez ver ao mundo numa dada globalidade. Por isso

\footnotetext{
${ }^{22}$ MERLEAU-PONTY, Maurice. Signes. Paris: Gallimard, 1960, p. 82.
} 
mesmo, a organização total de que trata da estrutura do criar não se iguala a um "fazer" fechado. Apesar de Schapiro anunciar que as pinturas dos impressionistas tratam de um mundo comum, entendemos que, ao se tratar de Cézanne, elas jamais foram recebidas pela sensação num fazer adequado, por exemplo, de formas e de tons.

Aliás, o que passa a ser incomum nesse percurso plástico e próprio de uma organização é a possibilidade de transpor a "confusão" como os impressionistas alcançavam as telas com imagens coloridas, dispersas, em cintilações tremeluzentes. Passamos a perceber que Cézanne enfrentará uma nova mentalidade. Os quadros dos impressionistas "estão demasiados presos ao instante, ao momento fugitivo e efémero. Cézanne não se contenta com traduzir directamente o que vê, ele quer penetrar pelo pensamento as manifestações da natureza, representar o que ela tem de duradouro, de imutável". ${ }^{23}$ Com essas reflexões, que acompanham diariamente um pintor dotado de dúvidas, nos deparamos com a última fase do percurso plástico.

\section{O fim de um percurso plástico e a herança de um mundo selvagem}

Não existe, a partir desse "novo" caminhar, um abandono da cor e da representação da natureza, pois com a organização da pintura, Cézanne tenta agora conceber a cor em seu termo mais absoluto e dar mais relevo à natureza; e, representar a natureza, não será um dado mimético, mas a experimentação de uma harmonia paralela à natureza, utilizando-se melhor dos espaços. O referido pintor repousa cores sólidas nas telas no lugar dos matizes e aperfeiçoa à cada manhã, a radical condição da visão. Vejamos tais peculiaridades em uma de suas naturezas-mortas:

${ }^{23}$ BECKS-MALORNY, Ulrike. Paul Cézanne (1839-1906): o pai da Arte Moderna. Op. cit., pp. 45-46. 


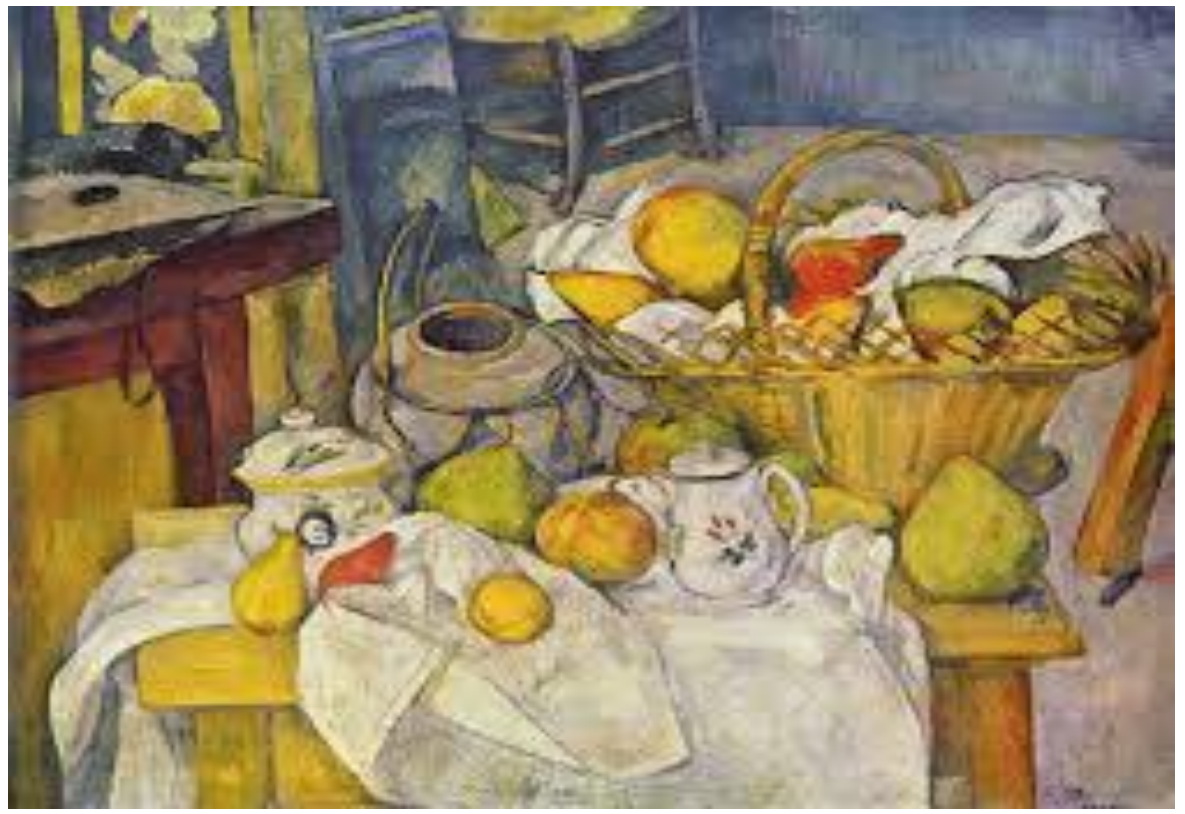

Fig. 4: Natureza-morta com cesta de fruta (A mesa de cozinha), 1888-1890

Não existe um detalhe apenas no centro ou no canto do quadro que, somado a outros, precisem anunciar o tema por meio de cores tremeluzentes: "Cézanne deixara de aceitar como axiomático quaisquer dos métodos tradicionais de pintura. Decidira partir da estaca zero, como se nenhuma pintura existisse antes dele". ${ }^{24} \mathrm{Em}$ tais "naturezas" usa a sensação de profundidade sem empregar jamais a linha como contornos de frutas, jarras, vasos ou mesas, bem como dos volumes que compõem as próprias imagens. Vejamos na seguinte passagem de Becks-Malorny, uma análise sobre a organização de Cézanne a partir da natureza-morta aqui referida:

[...] Cézanne cria um novo plano de realidade. Para isso, ele não tem necessidade nem de objetos artísticos nem de decorações sumptuosas: coisas mais simples são aquelas que melhor o ajudam a concretizar as suas concepções sobre a profundidade, a consistência e o peso numa estrutura plana. [...] Cézanne desenvolve a composição com a ajuda de pequenas manchas de cor repartidas sobre a tela e que, pouco a pouco, dão origem às formas e aos volumes dos objetos. ${ }^{25}$

\footnotetext{
${ }^{24}$ GOMBRICH, E. H. A história da arte. Op. cit., p. 543.

25 BECKS-MALORNY, Ulrike. Paul Cézanne (1839-1906): o pai da Arte Moderna. Op. cit., pp. 56-57.
} 
Ainda nestas telas com os temas das naturezas-mortas encontramos um Cézanne que jamais abandona uma organização pictórica que dista da harmonia e do equilíbrio entre as coisas simples pintadas, porque há um trabalho particular e subjetivo na maneira como vê o mundo, no entanto, a visão nunca se desarticula de um pensamento como parte do trabalho. "Muitíssimas vezes, Cézanne ficava longo tempo diante da tela sem nela aplicar a mínima pincelada". ${ }^{26}$ Os exemplos mais clássicos estão nas séries pintadas da Montanha de Santa Vitória, cujos troncos das árvores, os ramos, as folhas, as rochas, etc., possuem funções específicas, mas ao mesmo tempo simultâneas na ordem deste pensamento: de "lançar" a montanha à visão global.

$\mathrm{Na}$ elaboração de sua organização lançada à pintura em que ele trespassou os matizes coloridos dos impressionistas, além dos pigmentos ou pontos que assestavam apenas o detalhe de um canto do quadro, Cézanne "não tinha o propósito deliberado de distorcer a natureza; mas não lhe importava muito se ela tivesse que ser distorcida em alguns detalhes, [...] desde que isso o ajudasse a obter o efeito desejado". ${ }^{27}$ Ele encontra no espaço, a harmonia global do quadro; não há elementos isolados, mas paisagens que se oferecem diretamente ao olhar, e a visão dos "instantes" é convidada à duração, representada pelo sólido e pelo fluido das imagens, aspirando, portanto, a uma intemporalidade. A imagem-total é "uma realidade que não assenta no instante, mas que traz consigo a experiência da imutabilidade, da duração, do 'ser'". ${ }^{28}$ Passamos, desse modo, a perceber a questão merleau-pontyana de uma pintura selvagem capaz de decifrar o valor de reciprocidade entre o ser-sujeito e ser-mundo, pois a duração ontológica se confirma pela radical posição da visão no mundo. ${ }^{29}$ Merleau-Ponty radicaliza sua organização filosófica na medida em que busca todos os aspectos do Ser para a visão daquilo que se faz ver, mas também de certa encruzilhada

\footnotetext{
${ }^{26}$ Id. ibid.

${ }^{27}$ GOMBRICH, E. H. A história da arte. Op. cit., p. 544.

${ }^{28}$ BECKS-MALORNY, Ulrike. Paul Cézanne (1839-1906): o pai da Arte Moderna. Op. cit., pp. 71-72.

${ }^{29}$ Merleau-Ponty utiliza-se do conceito de "deiscência" da botânica para exprimir a abertura de seres que compõem o mundo para a visão do sujeito. Neste sentido, tanto a constância como a duração - acepções facilmente encontradas nas reflexões e pinturas de Cézanne -, estruturam também o sentido ontológico de globalidade. "Só ela [visão] nos ensina que seres diferentes, 'exteriores', estranhos um ao outro, estão todavia, absolutamente juntos - e é isto a 'simultaneidade'" (MERLEAU-PONTY, Maurice. O olho e o espírito. (Os pensadores) Trad. Marilena Chauí. São Paulo: Abril Cultural, 1975, p. 299).
} 
com o não visto, ou a invisibilidade que põe o improvável e o incerto como manifestações de sentido. Não tem como se afastar de uma possibilidade registrada no quadro pelo pintor: a do sentido; mesmo aquele sentido nas formas abstratas das imagens. Como diz nosso filósofo quando pensa em Paul Klee, o "impossível é dizer que aqui finda a natureza e começa o homem ou a expressão", ${ }^{30}$ mesmo porque as expressões podem representar a pintura abstrata e outras imagens pictóricas capazes de alcançar possíveis deformações pela intumescência das cores.

Esta fase de Cézanne - cujos autores em geral apontam para uma composição pré-cubista, a qual chamamos de pintura selvagem -, que influenciou as bases do pensamento merleau-pontyano da nova ontologia ou ontologia carnal, tem como nova organização, a supressão das linhas e contornos para que os efeitos sejam melhor alcançados pela cor. "Se o pintor quer exprimir o mundo, é preciso que o arranjo das cores traga em si este Todo indivisível; de outra maneira, sua pintura será uma alusão às coisas e não as mostrará numa unidade imperiosa". ${ }^{31}$ Mas qual seria o principal interesse de Merleau-Ponty deixar-se envolver por uma pintura que concebe, na última fase, a intumescência das coisas pela cor, buscando o mundo primitivo pela decomposição?

Trata-se, por certo, de uma influência que traz em si, questões múltiplas, mas compreendidas em uma unidade. Por exemplo, o Ser bruto e selvagem coincide com o da natureza primitiva exposta como tecido e carne do mundo. É a fundamental inseparabilidade ontológica, também entendida como simultaneidade e reciprocidade. Aqui, o elemento para essa compreensão é a cor. A familiaridade das coisas é invadida, quando a cor entra em cena para provocar a ultrapassagem do que é habitual. Para Merleau-Ponty, a decomposição do quadro é capaz de acentuar aspectos que nunca foram antes percebidos. Ele nos diz: "o pintor que pensa e que procura a expressão começa por faltar ao mistério da aparição de alguém na natureza, renovada a cada vez que o olhamos $[\ldots]]^{\prime 3}$

\footnotetext{
30 Ibidem., p. 299.

${ }^{31}$ MERLEAU-PONTY, Maurice. Sens et non-sens. Paris: Gallimard, 1996, pp. 20-21.

32 Ibidem., p. 21.
} 
As cores de Cézanne no espaço passam a ser empregadas sob o efeito de transbordamento, constituindo uma atmosfera que não seja a reprodução objetiva do visual (o que é habitual e familiar), senão conferida à simplicidade mesma da visão que se faz muitas vezes pela tensão de conteúdos deformados e visivelmente vibrantes. Aliás, como afirma Merleau-Ponty, os paradoxos são fenômenos da expressão e se apresentam no pintor pela deformação contínua de seus toques, criando uma "lógica" original para seus quadros. Afirma o filósofo:

O sentido que Cézanne em seus quadros dará às coisas e aos rostos propunhase-Ihe no próprio mundo que lhe aparecia, nada mais fez que o liberar, são as próprias coisas e os próprios rostos tais quais via que pediam para assim serem pintados e Cézanne não disse mais do que queriam dizer. ${ }^{33}$

A percepção das imagens em Cézanne consiste na reconfiguração de um espaço que revoga a harmonia perfeita, deixa cessar a atitude de equilíbrio entre as coisas pintadas, pois muitas vezes, para ele, não importa se a tinta "cobriu" todos os recantos do quadro e busca com as deformações uma "ordem nascente [e] uma realidade inesgotável" ${ }^{34}$ Esta questão do espaço já se faz motivo constituinte no Impressionismo integral do pintor e, na fase final, dá ênfase à ruptura tradicional caracterizada pela perspectiva linear. Por isso mesmo, os espaços em branco, não cobertos pelas tintas, seriam como partes constituintes e expressivas do motivo. O uso sólido das cores contribui não somente para as deformações imagéticas, mas para um certo transbordamento antagônico dos efeitos que podem causar as luzes. Seria acreditar na topologia das cores que dispõe as imagens em sua ontogênese, muito mais do que oferecer as suas formas mais diretamente. Mas seguramente, as cores que não estão sozinhas no quadro, nos trazem uma materialidade, o mundo com sua diversidade, as coisas mais simples e tão pouco imagináveis. A cor conduz-nos ao coração das coisas e só assim se pode refletir sobre a sensível percepção dela nascida no interior da própria tela. Há no quadro o mistério que irradia o visível ligado que é à profundidade que também se harmonizada com a cor e com o espaço. Seria a

\footnotetext{
33 Ibidem., p. 27.

34 Ibidem., p. 20.
} 
profundidade um dado exato no interior da pintura, confundindo-se com o espaço planimétrico do pintor?

Na organização pictórica de Cézanne, a profundidade não pode ser concebida como estrutura das imagens, mesmo considerando-se a ligação dela com as cores e com o espaço. A profundidade é dimensão; abertura ao indeterminado e ao secreto, abertura a um poder latente. Sobre essa questão, Merleau-Ponty enfrentará um percurso no interior de sua própria ontologia: a profundidade como irradiação do Ser em $O$ olho e o espírito, aquela que "está em todos os modos do espaço, e na forma igualmente ${ }^{\prime 35}$, torna-se duplamente uma profundidade ontológica em $O$ visível e $O$ invisível, quando o pintor continua a dar forma às coisas, agora num conflito harmônico - porém, instável - entre as cores, e quando ela é dimensão originária do visível que se dá a ver na multiplicidade das formas, espécie de desequilíbrio radical (selvageria), que nos convida constantemente à iniciação da experiência do mundo. Ao ser evidenciada tal "iniciação" é como se pensássemos num ciclo que se fecha, quando um pintor como Cézanne, traz às telas, a invisibilidade do visível, o espaço original. Como afirma JeanYves Mercury, "existe um segredo da profundidade e um milagre da pintura sobre um fundo de convivência carnal originário" ${ }^{36} \mathrm{O}$ ciclo a que nos referimos é o retorno crítico de Merleau-Ponty ao mundo dado, à tradição clássica da pintura com a concepção do perspectivismo planimétrico, também à pura representação e seu caráter normativo. ${ }^{37}$

\footnotetext{
35 MERLEAU-PONTY, Maurice. O olho e o espirito. Op. cit., p. 293.

${ }^{36}$ MERCURY, Jean-Yves. La chair du visible: Paul Cézanne et Merleau-Ponty. Paris: L'Harmattan, 2005, p. 77.

${ }^{37}$ Durante esses escritos evidenciamos em momentos diferentes a questão da pintura clássica como pura representação de um mundo claro e distinto, mostrando que o pintor aqui pensado para a proposta de um percurso plástico, refletiu com a pintura, a criação de um mundo "diferente". Dessa forma, o que pensamos sobre o caráter normativo da pintura é encontrado em Descartes o seu principal fundamento. Nosso filósofo analisa a relação do pensamento cartesiano com a instituição de normas clássicas para ser pensada a pintura. Merleau-Ponty elucida, a partir das Notes de cours de 1959-1961 sobre a ontologia cartesiana, as noções de luz e cor projetadas por aquele pensador moderno, que pretendeu reconstituir o visível a partir de representações racionais sem levar em consideração as nossas relações com o mundo vivido. Aliás, manipular o mundo sem habitá-lo é próprio da filosofia cartesiana. Assim, Merleau-Ponty dedica-se em vários textos e cursos à compreensão de Descartes e da obra A dióptrica, afirmando de tal filosofia uma sustentação ilusória do mundo. "A Dióptrica de Descartes [...] é o breviário de um pensamento que não mais quer assediar o visível e decide reconstruí-lo segundo o modelo que dele se proporciona" (MERLEAU-PONTY, Maurice. O olho e o espírito. Op. cit., p. 284).
} 
Acreditamos que, nas imagens do "último" Cézanne, exista o "reconhecimento" do mundo que aprofunda a ação do olhar do sujeito como a experiência lógica, conforme diz Merleau-Ponty, "alusiva ao mundo percebido". ${ }^{8}$ Não se trata de um reconhecimento pleno do real, mas de uma solicitação da coisa vista. Sem dúvida, teremos constantemente, nas leituras deste filósofo, a não existência de uma conformidade "pura" das coisas como modelo exterior. É como se compreendêssemos que o quadro possui, de fato, um limite que encerra a imagem, mas ao um tempo "durável" a que Cézanne nos impele ao efeito reversivo da natureza pintada nesta mesma imagem, tal circunscrição desaparece. Um tempo mais que maduro para a visão que invade o quadro na relação carnal com a imagem que pretende saltar da paisagem rumo ao ser. As "coisas" foram organizadas para a duração do olhar e do pensamento, logo, não existe a figuração direta das imagens, mas fulguração do ser; "descoberta" que se estende além da superfície - e graças à cor. ${ }^{39}$ No quadro abaixo percebemos essa relação ontológica, a partir das séries pintadas sobre o motivo da montanha de Aix-en-Provence. Escolhemos uma em especial, das variadas montanhas pintadas entre 1904 a 1906: A montanha Sainte-Victoire, vista dos Lauves.

\footnotetext{
${ }^{38}$ MERLEAU-PONTY, Maurice. Signos. Op. cit., p. 58-59.

${ }^{39}$ Vale a insistência de que a cor em Cézanne é o principal "instrumento" de sua "organização" pictórica, sobretudo nesta fase a que chamamos de "pintura selvagem". A cor é o único elemento capaz de dar unidade às coisas da imagem, que jamais estarão expostas isoladamente. No caso da luz muito bem arquitetada do campo impressionista à esta fase, ela só existe enquanto a presença das cores em composição.
} 


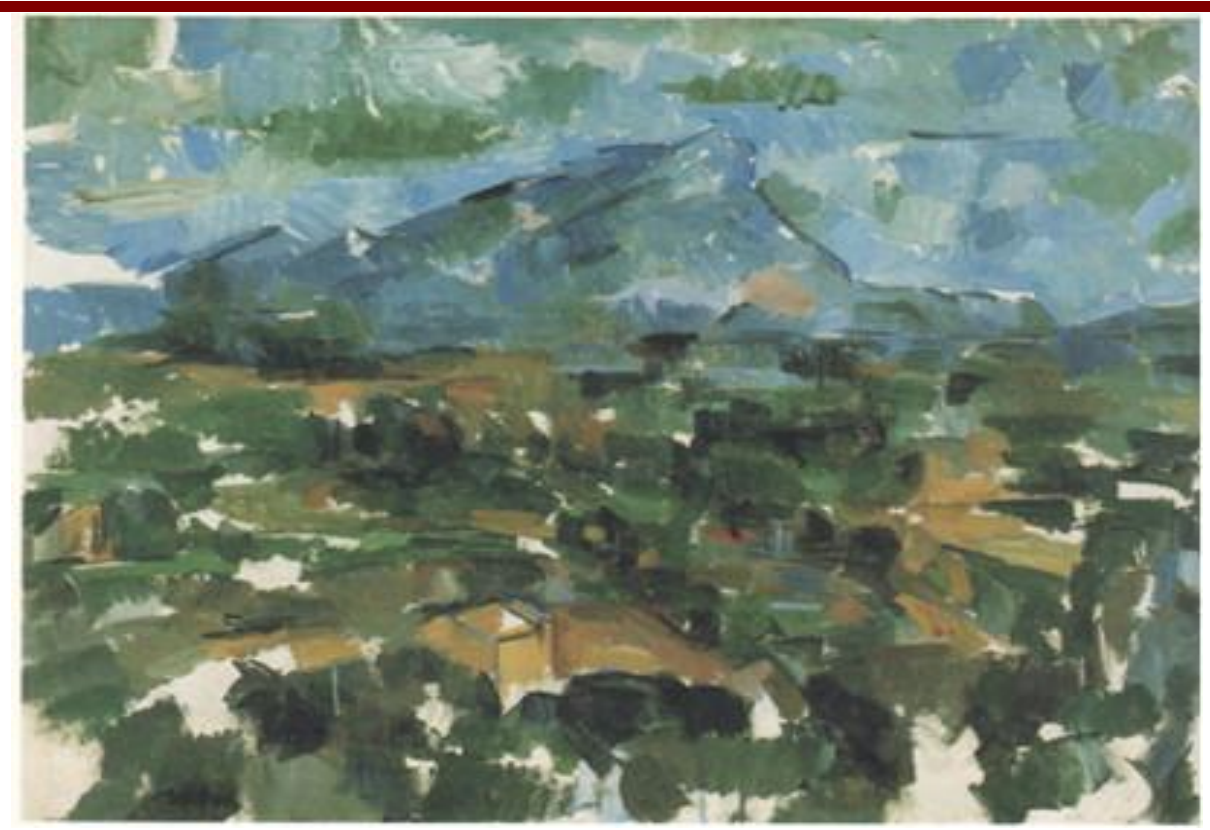

Fig. 5: A Montanha de Sainte-Victoire, vista dos Lauves, 1904-1906

No presente quadro, Cézanne está voltado à solidez das formas, à vibração de cores que faz brotar uma luz diferenciada no todo, além do prolongamento de um espaço que "suplica" a sua eclosão, representado pelas pinceladas brancas. Ao analisarmos tal imagem, ver-se-á a composição de um único plano existente desde a montanha situada atrás do quadro e sob um céu abafado e soturno, salpicado de verde que é a mesma cor da vegetação. O espaço do quadro é, portanto, um todo dinâmico, graças ao movimento das cores amareladas que reluzem a base figurada pela planície e que se ligam aos mesmos tons do azul do céu, meio que "derramados" na planície e entre as improváveis casas. O pintor consegue mostrar um espaço onde tal movimento retesado das cores abre um poder "corrompido" das imagens, parecendo que não existe plano algum nesta pintura sólida. ${ }^{40}$ Seria a continuidade de uma sensação originária do mundo, agora selvagem?

\footnotetext{
${ }^{40}$ Como ainda indica Becks-Malorny sobre a referida montanha, "Cézanne compõe o seu motivo a partir de manchas claras e carregadas que só evocam uma paisagem se forem vistas na sua globalidade. 0 céu retoma a cor do solo, os brancos deixam o quadro 'em suspenso'. É com tais efeitos que Cézanne acentua o carácter bidimensional do suporte pictórico" (BECKS-MALORNY, Ulrike. Paul Cézanne (1839-1906): o pai da Arte Moderna. Op. cit., p. 76. Grifo nosso).
} 
Como contribuição à essa questão e a fim de concluir este trabalho, nos reportamos a Gilles Deleuze no momento em que compara a sensação das pinturas do Cézanne "selvagem" com as pinturas de Francis Bacon (1909-1992):

Eu como espectador só experimento a sensação entrando no quadro, tendo acesso à unidade daquele que sente e do que é sentido. A lição de Cézanne vai além dos impressionistas: não é no jogo "livre" ou desencarnado da luz e da cor (impressões) que está a Sensação, mas no corpo, mesmo que no corpo de uma maçã. [...] O que está pintado no quadro é o corpo, não enquanto representado como objeto, mas enquanto vivido como experimentando determinada sensação. ${ }^{41}$

\section{Considerações finais}

Nossas reflexões aqui expostas buscaram destacar um "percurso" plástico bastante caro ao pensamento de Merleau-Ponty que empreendeu, por sua vez, a maior ligação de uma filosofia com a estética pictórica na contemporaneidade. Entre as diversas áreas que podemos transitar com este pensamento, escolhemos a estética merleau-pontyana na condição das imagens pictóricas, que a nosso ver explicita a valorização que este filósofo deu à pintura como a arte que melhor figura a relação da filosofia na compreensão do sujeito da experiência perceptiva e carnal com o mundo. Por isso, não somente o presente pensamento refaz uma reflexão sobre o mundo objetivo e dado, como também "lança" o sujeito perceptivo ao desacordo da pura representação do mundo vivido.

Por isso mesmo, direcionamos nossa principal questão a respeito das pinturas de Paul Cézanne para o princípio de organização das suas imagens como a forma de conceber e apreender as criações tão próximas à natureza mundana, e como a pintura que, em diversas fases, promoveu uma organização básica e singular de situação dos sujeitos face às experiências mundanas. Tal organização não pode ser concebida como a dedicação de um pintor que requer apenas um esquema material de concepção imagética. Muito mais que isso, Cézanne estabeleceu com o significado de

\footnotetext{
${ }^{41}$ DELEUZE, Gilles. Francis Bacon: lógica da sensação. Trad. Roberto Machado. Rio de Janeiro: Jorge Zahar Editor, 2007, pp. 42-43. Mais adiante, Deleuze afirma: "Teremos a ocasião de ver em que medida Bacon é cézanneano, muito mais que discípulo de Cézanne" (Ibidem., p. 44).
} 
espaço da tela, a noção de expansão dos "espaços" capazes de firmar um encontro sempre possível do sujeito da percepção com o fenômeno do aparecer e, mais tarde, com a carne sensível do mundo.

Encontramos na tese da organização de Cézanne, a vontade que este teve em pintar os instantes simples do mundo que nos rodeiam, desde o seu romantismo inicial, passando pelo "clássico" Impressionismo e até desenvolver uma criação madura à qual denominamos de pintura selvagem. Assim, estabelecemos a partir dessa questão uma influência direta, porque não dizer, paralela com o trabalho de um pensamento, ou seja, Merleau-Ponty também organizou uma reflexão que atenta para a expressividade do corpo próprio, sustentando na pintura a dinâmica plausível com que o pintor "ancora" seu corpo no ato de criação. Entendemos o corpo como o suporte onde acontece esta relação doadora de sentidos e a partir de uma organização existencial em que ele aparece sempre como postura diante de tarefas possíveis.

\section{Referências bibliográficas}

BECKS-MALORNY, Ulrike. Paul Cézanne (1839-1906): o pai da Arte Moderna. Lisboa: Taschen, 1996.

BONAN, Ronald. Aprendre à philosopher avec Merleau-Ponty. Paris: Ellipses.

CÉZANNE, Paul. In: BARNES, Rachel (coord.). Os artistas falam de si próprios: Cézanne. Trad. Maria Celeste Guerra Nogueira. Lisboa: Dinalivro, 1993.

DELEUZE, Gilles. Francis Bacon: lógica da sensação. Trad. Roberto Machado. Rio de Janeiro: Jorge Zahar Editor, 2007. DESCARTES, René. A dióptrica. Discursos i, ii, iii, iv e viii. Trad. José Portugal dos Santos Ramos. Supervisão Pablo Rubén Mariconda. In: Scientiae studia. Revista Latino-Americana de Filosofia e História da Ciência. São Paulo, v. 8, n. 3, p. 451-486, 2010.

GOMBRICH, E. H. A história da arte. Trad. Álvaro Cabral. 16a ed. Rio de Janeiro: LTC, 1995.

MERCURY, Jean-Yves. La chair du visible: Paul Cézanne et Merleau-Ponty. Paris: L'Harmattan, 2005.

MERLEAU-PONTY, Maurice. A dúvida de Cézanne. (Os pensadores) Trad. Marilena Chauí. São Paulo: Abril Cultural, 1975.

. Fenomenologia da percepção. Trad. Carlos Alberto Ribeiro de Moura. 2a ed. São Paulo: Martins Fontes, 1999. 
Fontes, 1991.

Signos. Trad. Maria Ermantina Galvão Gomes Pereira. São Paulo: Martins

. A prosa do mundo. Trad. Paulo Neves. Edição e prefácio de Claude Lefort. São Paulo: Cosac \& Naif, 2002.

. Signes. Paris: Gallimard, 1960.

. O olho e o espírito. (Os pensadores) Trad. Marilena Chauí. São Paulo: Abril Cultural, 1975.

Sens et non-sens. Paris: Gallimard, 1996.

. O visível e o invisível. Trad. José Artur Gianotti e Armando Mora d'Oliveira. Prefácio Claude Lefort. São Paulo: Perspectiva, 1999.

PEREIRA, Marcelo Duprat. A expressão da natureza na obra de Paul Cézanne. Rio de Janeiro: Sette Letras, 1998.

RILKE, Rainer Maria. Cartas sobre Cézanne. Trad. e prefácio de Pedro Süssekind. 5.ed. Rio de Janeiro: 7Letras, 2006.

SCHAPIRO, Meyer. Impressionismo: reflexões e percepções. Trad. Ana Luiza Dantas Borges. Prefácio de Sônia Salzstein. São Paulo: Cosac \& Naify, 2002. 